\title{
What can the CF registry tell us about rare CFTR-mutations? A Belgian study
}

\author{
E. De Wachter ${ }^{1 *}$, M. Thomas ${ }^{2}$, S. S. Wanyama ${ }^{2}$, S. Seneca ${ }^{3}$ and A. Malfroot ${ }^{1}$
}

\begin{abstract}
Background: CFTR2 provides clinical and functional information of the most common CFTR-mutations. Rare mutations (RMs) occur in only a few patients with limited reported clinical data. Their role in CF-disease liability is hardly documented.

Methods: Belgian CF-Registry 2013 data were analyzed to identify CF with at least 1 RM (CF+RM). Clinical data and sweat chloride of $\mathrm{CF}_{+\mathrm{RM}}$ were compared to CF-controls, carrying 2 class 1 to 3 mutations ( $\mathrm{CF}_{\text {classic }}$ ). Disease severity was compared between both groups. To avoid bias in the comparison, transplanted patients were excluded from each group.

Results: Seventy-seven $C_{+}$RM were identified $(77 / 1183=6.5 \%)$. Sixty-four different RM were detected, of which 21 had not been previously reported. All RMs, corresponding to HGVS (Human Genome Variation Society) nomenclature, were listed in supplementary data.

Seven transplanted $\mathrm{CF}_{+\mathrm{RM}}$ were excluded for further analysis. $\mathrm{CF}_{+\mathrm{RM}}$ had higher age at diagnosis [median (IQR)] [3.7 y $(0.3-18.3)$ vs. $0.3 y(0.1-2,0)(p<0.0001)]$, lower sweat chloride $[96 \mathrm{mmol} / \mathrm{L}(64-107)$ vs. $104 \mathrm{mmol} / \mathrm{L}(97-115)$ $(p<0.0001)]$, higher $\mathrm{FEV}_{1} \%$ pred [77\%pred (58-96) vs. 68\%pred (48-86) $\left.(p=0.017)\right]$, were less frequently pancreatic insufficient [56\% vs. 98\% ( $p<0.0001)]$, Pseudomonas aeruginosa colonized [24\% vs. 44\% ( $p=0.0093)]$ and needed fewer IV antibiotics [36\% vs. $51 \%(p=0.041)]$ than $C_{\text {classic. }}$ However, a wide spectrum of disease severity was seen amongst $C F_{+R M}$.

Conclusions: CF-patients with a RM cover $6.5 \%$ of the Belgian CF-population. Rare mutations can be found in severely ill patients, but more often in late diagnosed, pancreatic sufficient patients.
\end{abstract}

Keywords: Cystic fibrosis, CF-registry study, Genotype-phenotype correlation, Disease liability, Rare CFTR-mutations

\section{Background}

Cystic fibrosis (CF) is characterized by a wide spectrum of disease severity, ranging from end-stage lung disease at young age to mild symptoms in adulthood. The heterogeneity of mutations on the CFTR-gene is in some way responsible for this finding. However, other genetic modifiers and environmental factors influence disease liability and therefore CFTR-mutations alone should not be used to predict disease severity in CF [1-5].

Since the discovery of the Cystic Fibrosis Transmembrane Regulator (CFTR) gene in 1989 [6], more than 2000 mutations have been detected and reported in the CFTR1-database (CF Mutation Database) [7]. However, not all of these variants are disease-causing. Neutral variants are more frequently seen in the healthy population (eg. M470 V, I148T). Some can cause CF in

\footnotetext{
* Correspondence: elke.dewachter@uzbrussel.be

${ }^{1}$ CF Clinic, Universitair Ziekenhuis Brussel, Vrije Universiteit Brussel,

Laarbeeklaan 101, 1090 Brussels, Belgium

Full list of author information is available at the end of the article
}

some individuals and no disease in others (eg. R117H, $\mathrm{D} 1152 \mathrm{H})$ and are designated as mutations with varying clinical consequences (VCC) [4, 8]. A wide distribution of CFTR variants among different ethnicities and countries has been well described, with F508del being the most prevalent CF-causing mutation worldwide $[4,9]$.

The aim of CFTR2 (Clinical and Functional Translation of CFTR) was to assess the disease liability of most common CFTR-mutations. Current information in the CFTR2database is based on phenotypical data from CF-registries of different countries, population studies in healthy subjects and carriers in combination with in vitro functional testing in HeLa and Fisher rat thyroid cells $[4,8]$. In August 2015, 276 mutations were listed in CFTR2 and some genotype-phenotype correlations had been reported for most variants [10]. However, the CFTR2-core team warns users of this website database not to use CFTR2 to predict phenotypic outcomes [1-4]. However, CFTR2 may be helpful in diagnostic dilemmas by grouping mutations 
in 3 different categories (CF-causing, VCC, and Non-CFcausing) [11]. According to the consensus statement, detection of $2 \mathrm{CF}$-causing mutations in trans is one of the criteria to meet in making a diagnosis of $\mathrm{CF}$ in individuals with suggestive clinical features [12-14].

Despite attempts to expand CFTR2 to rather rare mutations, little is known about variants that are not listed in CFTR2 and seen in only few people with CF (PWCF) worldwide. No clear definition of a 'rare CFTR mutation' (RM) can be found in the literature. We deem that all CFTR mutations not described in CFTR2 could be contemplated as a RM. With the use of extended genotyping, clinicians are more often confronted with the detection of a rare variant of unknown clinical consequence in a patient with suggestive symptoms. Especially in cases of intermediate sweat test values $(30-60 \mathrm{mmol} / \mathrm{L}), \mathrm{CF}$ diagnosis can be hard to make, as this condition can be consistent with CF, CFTR-RD (CFTR-related disorder) or healthy CFTR-carriers. Nasal potential difference (NPD) measurements, intestinal current measurements (ICM) or other in vivo and in vitro functional testing enable a better understanding of the pathogenicity of these mutations and help in refining a diagnosis in these individuals with questionable CF [14-18]. Still, these tests are not easily available and standardized reference data are lacking [19-21]. Results of these functional diagnostic tests are rarely reported to national CF-Registries. However, most of them collect CFTR-genotyping data. Therefore, the CF-registry could be a useful tool to identify CF-patients with uncommon mutations.

We used the Belgian CF-registry database to study CF patients carrying at least $1 \mathrm{RM}$. Our first aim was to identify all RM and investigate if a RM had been previously reported in CFTR1 or not. Secondly, we compared these patients with age and gender-matched controls with classic CF (carrying 2 class 1-3 mutations) [16, 22], to find out if patients with a RM as a group, differ in disease severity by comparing clinical and sweat test data. Finally, we identified RMs that were seen in patients with sweat chloride values below the diagnostic threshold of $60 \mathrm{mmol} / \mathrm{L}$, as these mutations may be assigned as questionable disease causing mutations.

\section{Methods}

The Belgian CF-registry database of 2013 (BCFR2013) was used for this retrospective study. CF-cases referred to as $\mathrm{CF}_{+\mathrm{RM}}$, had at least $1 \mathrm{RM}$ defined as a mutation not listed in the CFTR2-database. (Version August 2015) [10]. Some RMs had been previously reported in the CFTR1 database (CFTR1RM) [7], while others had not been previously reported (Non-CFTR1RM).

$\mathrm{CF}$-controls, referred to as $\mathrm{CF}_{\text {classic, }}$ were preferably F508del/F508del, or had another class 1-3 CFTRmutation on each allele. For the comparison study each
$\mathrm{CF}_{+\mathrm{RM}}$ was age-and gender-matched with $2 \mathrm{CF}_{\text {classic- }}$ Transplant patients were excluded in each group to avoid bias in comparing respiratory outcomes.

The following variables were analyzed for each study group: age (defined as age on 31st December 2013), age at diagnosis, sweat chloride, $\mathrm{FEV}_{1} \%$ pred, BMI, patients receiving IV antibiotics during 2013, pancreatic status, chronic infection with Pseudomonas aeruginosa (PA), CFliver disease and CFRD (CF related diabetes). $\mathrm{FEV}_{1} \%$ pred was defined as percentage predicted $\mathrm{FEV}_{1}$, using Wang reference values [23] for males between 6 and 17 years and female patients between 6 and 15 years of age, whilst Hankinson reference values were used for males 18 years and above and females 16 years and above [24]. $\mathrm{FEV}_{1}$ \%pred was the result of the last pulmonary function test performed in 2013. BMI was analyzed according to Cachera Z-score, using reference values in males between 0 and 58 years and females between 0 and 56 years [25]. Exocrine pancreatic insufficiency (PI) was defined as fecal elastase $<200 \mu \mathrm{g} / \mathrm{g}$. Chronic infection with $P A$ was defined according to the Leeds criteria [26]. CF-liver disease was considered in cases of cirrhosis with portal hypertension and CFRD if treatment with insulin was required.

'Missing data' were data which were not provided by the CF-centre. 'Not identified' data were data that could not be demonstrated despite further investigation. Results that seemed to be inconsistent or unclear were double checked with the CF-centre.

All PWCF included in the Belgian CF-Registry signed informed consent to have their data collected and entered into the database as a research tool. Registry data were compliant to Belgian data protection laws.

\section{Statistics}

The data are described using frequencies and proportions, n (\%) and mean (standard deviation, SD) or medians (interquartile range, $\mathrm{IQR}$ ).

To compare the continuous and count data the Mann-Whitney two sample rank test was used where study outcomes failed the normality test. Otherwise, the unpaired Student's t-test was applied. Differences in cross-tabulated data including the distribution of mutations, CFRD, liver disease, chronic $P A$ infection and pancreatic status between both groups were tested using the $x^{2}$ statistic. The Fisher's exact test was used for small counts $(\leq 5)$, in some cases with continuity correction.

All tests were two sided and considered statistically significant at type I error $<0.05$. Where multiple testing was done, the Bonferroni adjustment was used. The analyses were performed using $\mathrm{SAS}^{\ominus}$ version 9.3 (SAS Institute Inc.).

\section{Results}

BCFR2013 data included 1186 PWCF, of which 3 had missing genotype data (Table 1). Of the remaining 1183, 
Table 1 BCFR2013-patients, according to their mutations

\begin{tabular}{|c|c|c|c|c|c|c|c|c|}
\hline \multirow[t]{3}{*}{ MUTATION 1} & \multicolumn{8}{|l|}{ MUTATION 2} \\
\hline & & \multicolumn{3}{|l|}{ In CFTR2 } & \multicolumn{2}{|c|}{ Not in CFTR2 } & \multirow[t]{2}{*}{ Not identified } & \multirow[t]{2}{*}{ Total } \\
\hline & & CF-causing & Non CF causing & VCC & CFTR1 & Non-CFTR1 & & \\
\hline \multirow[t]{3}{*}{ In CFTR2 } & CF-causing & 995 & 8 & 49 & 51 & 20 & 34 & 1157 \\
\hline & Non CF causing & - & 1 & - & - & - & - & 1 \\
\hline & VCC & - & - & 3 & - & - & - & 3 \\
\hline \multirow[t]{2}{*}{ Not in CFTR2 } & CFTR1 & - & - & - & 2 & - & $2^{a}$ & 4 \\
\hline & Non-CFTR1 & - & - & - & 3 & 1 & - & 4 \\
\hline Not identified & & - & - & - & - & - & 14 & 14 \\
\hline Total & & 995 & 9 & 52 & 56 & 21 & 50 & 1183 \\
\hline
\end{tabular}

2 patients, carrying 1 RM and 1 'not identified' mutation are excluded from analysis $\left({ }^{\mathrm{a}}\right.$ )

Bold: mutations not reported in CFTR2, subsequently defined as a RM

$995(84.1 \%)$ had a CFTR2-CF-causing mutation on each allele. Nine patients $(0.7 \%)$ carried at least 1 non-CFcausing variant and 52 patients $(4.4 \%)$ had at least 1 mutation with VCC, as described by CFTR2 [10]. Fifty patients (4.2\%) carried at least 1 mutation that was not identified, of whom $14(1.2 \%)$ had no mutation identified at all.

\section{Different mutation nomenclature in the registry (see Additional file 1)}

As mutations were listed in the way the CF center entered them in the BCFR2013, an attempt was made to reconcile these names with the corresponding HGVS (Human Genome Variation Society) nomenclature (c.DNA and protein name) [27, 28]. Inconsistency in reporting variants lead to confusion in five mutations, incorrectly suggesting these were RM. Consequently, these were removed for further analysis.

\section{Study population}

Seventy-nine CF patients carried at least $1 \mathrm{RM}$. Two had no second CFTR-mutation identified and were therefore excluded from the study (Table 1 ). Seventy-seven $\mathrm{CF}_{+\mathrm{RM}}$ represented $6.5 \%$ of the BCFR2013-population. Seven CF + RM underwent lung transplantation and were excluded from the comparison study. For the remaining $70 \mathrm{CF}_{+\mathrm{RM}}$, $140 \mathrm{CF}_{\text {classic }}$-non transplanted patients were selected, of which 129 were homozygous F508del and 11 carried 2 class 1-3 mutations on each allele, other than F508del.

\section{$C_{+R M}$ with at least 1 RM documented in CFTR1}

Fifty-six $\mathrm{CF}_{+\mathrm{RM}}$ carried at least 1 CFTR1-documented RM (CFTR1RM) (Table 1). Fifty-one/56 (91\%) were compound heterozygous with a CF-causing mutation; 37 carried F508del, 3 had 1717-1G > A, 2 had $2183 \mathrm{AA}>\mathrm{G}$ and 2 had N1303 $\mathrm{K}$ in trans, while the following mutations were found once in trans: 3272-
26A > G, 394delTT, Q890X, 4218insT, G542X, R347P, $2789+5 \mathrm{G}>\mathrm{A}$.

Two $\mathrm{CF}_{+\mathrm{RM}}$ carried a CFTR1RM on each allele (1 homozygous, 1 compound heterozygous). Three subjects had in trans of their CFTR1RM another RM, which had not previously been listed in the CFTR1 database (Non-CFTR1RM). Altogether 43 different CFTR1RM were found in the BCFR-population (Table 2).

L165S was seen in 5 PWCF, with a CF-causing mutation in trans, being the most prevalent RM in Belgium.

Table 2 Rare mutations found in the Belgian CF-population and their prevalence

\begin{tabular}{|c|c|c|}
\hline Prevalence & CFTR1-RM & Non-CFTR1-RM \\
\hline $5 \times$ & L165S & \\
\hline $3 \times$ & Y913C, M1137R & 1002-1113_110delGAAT \\
\hline $2 \times$ & $\begin{array}{l}\text { G458 V, E656X, W882X, } \\
\text { 1833delT, L159S }\end{array}$ & $\begin{array}{l}\text { Y913S, IVS16-977_IVS17b } \\
+ \text { 247del2514 }\end{array}$ \\
\hline $1 \times$ & 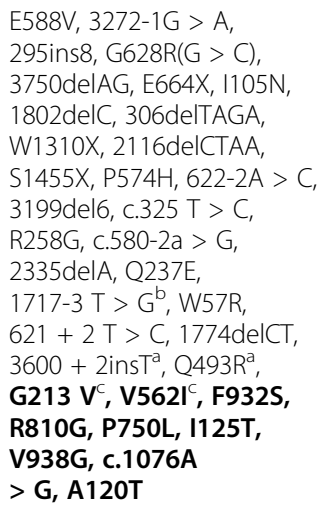 & $\begin{array}{l}\text { 186-2A > G, 3730A > } \\
\text { TCT }^{\text {b }}, 2005 \text { delTA } \\
\text { c. K464E, } \\
\text { c.1819_1902del, } \\
\text { c.1648_1652dupATCATc, } \\
\text { CFTRdelePr-1, G85R, } \\
\text { c.2909-?_3367 +?del', } \\
\text { c.4243-1G > A, p.Gln652x, } \\
\text { c.4243_4244insCTGT, } \\
\text { c.25dupG, p.Val1240_ } \\
\text { GIn1291del, c.461dup } \\
\text { (p.ala155fs), g.3464_ } \\
\text { 3471dupTCATTGCT; } \\
\text { V1198 M, G551R, T854A }\end{array}$ \\
\hline total & 43 mutations & 21 mutations \\
\hline
\end{tabular}

Mutations are written as they are documented in the BCFR2013. For translation into HGVS nomenclature: see Additional file 1

bold: mutations associated with sweat chloride $<60 \mathrm{mmol} / \mathrm{L}$

${ }^{a}$ mutation in trans with a Non-CFTR1-RM

bomozygous for this RM

' mutation in trans with a CFTR1-RM 
Based on the registry data, we assumed that 2 patients were siblings and the others are not related.

\section{$C_{+R M}$ with at least 1 RM not documented in CFTR1}

Twenty-four $\mathrm{CF}_{+\mathrm{RM}}$ carried at least $1 \mathrm{RM}$, not documented in CFTR1 (Non-CFTR1RM) (Table 1). Twenty/ 24 (83\%) were compound heterozygous with a CFcausing mutation, of whom 12 carried F508del in trans. The following mutations were seen once in trans with the Non-CFTR1RM: $711+1 \mathrm{G}>\mathrm{T}$, N1303 K, A455E, 360X, R764X, $3849+10 \mathrm{kbC}>\mathrm{T}, \mathrm{G} 542 \mathrm{X}$, $2789+5 G>A$. Three $\mathrm{CF}_{+\mathrm{RM}}$ carried in trans a CFTR1RM, hereby belonging to both groups. (See paragraph 4.2.1) One $\mathrm{CF}_{+\mathrm{RM}}$ was homozygous for the NonCFTR1RM. Altogether 21 different Non-CFTR1RM were found in the Belgian CF-population (Table 2).

\section{$\mathrm{CF}_{+R M}$ with sweat chloride $<60 \mathrm{mmol} / \mathrm{L}$ or no sweat test results (Table 3 )}

Fourteen/77 $\mathrm{CF}_{+\mathrm{RM}}(18 \%)$ did not have sweat tests in the CF-range. The lowest sweat chloride $(28 \mathrm{mmol} / \mathrm{L})$ was seen in a $\mathrm{CF}_{+\mathrm{RM}}$ with a RM on both alleles.

Seven adults with CFTR1RM had no sweat test data (missing data). All had an early diagnosis (before the age of 2 years) and were mainly pancreatic insufficient (PI): 5/7 PI, 1/7 PS and 1/7 missing data.

\section{$\mathrm{CF}_{+R M}$ cases with lung transplantation (Table 4)}

Seven $\mathrm{CF}_{+\mathrm{RM}}$ underwent lung transplantation. All carried F508del in trans of their RM. Importantly, age at diagnosis differed in this group (range $0-13$ years). They all had clear abnormal sweat tests (1 missing) and were mostly PI. This group was excluded for comparison between $\mathrm{CF}_{+\mathrm{RM}}$ and $\mathrm{CF}_{\text {classic }}$.

\section{Comparison of $\mathrm{CF}_{+\mathrm{RM}}$ with $\mathrm{CF}_{\text {classic }}$ (Table 5)}

Each $\mathrm{CF}_{+\mathrm{RM}}(n=70)$ was matched for age and gender with $2 \mathrm{CF}_{\text {classic }}(n=140)$.

Age at diagnosis was statistically higher in $\mathrm{CF}_{+\mathrm{RM}}$ compared to $\mathrm{CF}_{\text {classic }}(p<0.0001) . \mathrm{CF}_{+\mathrm{RM}}$ had lower sweat chloride levels than $\mathrm{CF}_{\text {classic }}(p<0.0001)$. All $\mathrm{CF}_{\text {classic, }}$ for whom sweat test data were available, had a sweat chloride $>60 \mathrm{mmol} / \mathrm{L}$. This was only the case in $79 \%$ of $\mathrm{CF}_{+\mathrm{RM}}$. Compared to $\mathrm{CF}_{\text {classic }}$, this is a statistically significant difference $(p<0.0001) . \mathrm{CF}_{+\mathrm{RM}}$ had better FEV1\%pred compared to $\mathrm{CF}_{\text {classic }}$ $(p=0.0166)$ and were less frequently $P A$-colonized than $\mathrm{CF}_{\text {classic }}(p=0.0093) . \mathrm{CF}_{+\mathrm{RM}}$ were less likely to receive IV antibiotics than $\mathrm{CF}_{\text {classic }}(p=0.0414)$ and were less frequently PI $(p<0.0001)$. No difference could be seen on BMI z-score, CF-liver disease or CFRD between the two groups.

\section{Discussion}

The BCFR2013 revealed that $84.1 \%$ of the Belgian CF patients could have been diagnosed based only on genetic testing, using sequencing and CFTR2-criteria. However, other non-genetic diagnostic tests (sweat test, NPD, ICM) are needed to confirm a CF-diagnosis in patients with at least 1 mutation with VCC (4.4\%), patients who have no second mutation identified (4.2\%) and those who carry at least $1 \mathrm{RM}(6.5 \%)$. This is consistent with the findings of Ooi et al. who demonstrated that the use of mutations as a diagnostic tool is of limited value compared to functional testing such as sweat testing and NPD, especially in people with mild clinical presentation $[29,30]$. In $4.4 \%$ of the BCFR-population, at least 1 CFTR-mutation is missing or unknown. Some of these PWCF may carry a rare, not yet identified CFTRmutation. Extended sequencing analysis of the whole CFTR gene should be proposed in these individuals.

Table 3 RM with sweat chloride $<60 \mathrm{mmol} / \mathrm{L}$

\begin{tabular}{|c|c|c|c|c|c|c|c|}
\hline CFTR1-RM & Trans mutation & Sweat $\mathrm{Cl}\left({ }^{d}\right)$ & Panc & Non-CFTR1-RM & Trans mutation & Sweat $\mathrm{Cl}\left({ }^{\mathrm{d}}\right)$ & Panc \\
\hline G213 V & $\left.\mathrm{V} 562\right|^{a}$ & 28 & $\mathrm{Pl}$ & 1002-1113_110delGAAT & F508del & 49 & PS \\
\hline F932S & F508del & 30 & $\mathrm{Pl}$ & 1002-1113_110delGAAT & F508del & 38 & PS \\
\hline R810G & F508del & 32 & PS & 1002-1113_110delGAAT & F508del & 48 & PS \\
\hline P750L & F508del & 36 & $\mathrm{Pl}$ & G551R & $3849+10 \mathrm{kbC}>\mathrm{T}$ & 30 & PS \\
\hline $1125 \mathrm{~T}$ & F508del & 36 & PS & T854A & G542X & 46 & PI \\
\hline V938G & F508del & 40 & PS & & & & \\
\hline $\mathrm{Q}^{3} 59 \mathrm{R}^{\mathrm{b}}$ & $1717-1 G>A$ & 45 & $\mathrm{Pl}$ & & & & \\
\hline A120T & F508del & 47 & $\mathrm{Pl}$ & & & & \\
\hline${\mathrm{L} 159 S^{\mathrm{C}}}$ & F508del & 55 & PS & & & & \\
\hline
\end{tabular}

Panc pancreatic status, PI pancreatic insufficient, $P S$ pancreatic sufficient ${ }^{\mathrm{a} C F T R 1-R M}$

${ }^{\mathrm{b}} \mathrm{Q} 359 \mathrm{R}=$ legacy name for $\mathrm{c} .1076 \mathrm{~A}>\mathrm{G}$, as mentioned in the registry

'Found in another subject with sweat chloride $>60 \mathrm{mmol} / \mathrm{L}$

$\mathrm{d}_{\text {in } \mathrm{mmol} / \mathrm{L}}$ 
Table $4 \mathrm{CF}_{+\mathrm{RM}}$ with lung transplantation

\begin{tabular}{llllll}
\hline CFTR1-RM & CFTR-RM & $\begin{array}{l}\text { Trans } \\
\text { mutation }\end{array}$ & $\begin{array}{l}\text { Age at } \\
\text { transplant }\end{array}$ & $\begin{array}{l}\text { Sweat } \\
\text { chloride } \\
\text { (mmol/L) }\end{array}$ & $\begin{array}{l}\text { Pancreatic } \\
\text { Status }\end{array}$ \\
\hline Y & E656X & F508del & 25-30y & 124 & PS \\
Y & Y913C & F508del & $30-35 y$ & 118 & PS \\
Y & 3750delAG & F508del & 25-30y & 112 & PI \\
Y & E664X & F508del & $30-35 y$ & Missing & PI \\
Y & M1137R & F508del & 25-30y & 101 & PI \\
Y & 1833delT & F508del & $30-35 y$ & 115 & Missing \\
N & IVS16- & F508del & 20-25y & 115 & PI \\
& 977_IVS17b & & & & \\
\hline
\end{tabular}

$P /$ pancreatic insufficient, $P S$ pancreatic sufficient

In this study 64 different RM were detected, of which 21 had not been previously reported. Belgium contributes data to CFTR1 and CFTR2. However, we should encourage $\mathrm{CF}$-centres to continue reporting their rare mutations to CFTR1 to overcome underreporting in the future. To our knowledge, L165S, the most prevalent RM in Belgium, has only been described in CFTR 1 in 2 French adults [7].

CF patients with at least $1 \mathrm{RM}$, as a group, had significantly more preserved pancreatic and pulmonary function than their CF-controls, carrying 2 class 1-3 mutations, explaining the significant differences in sweat chloride, the later diagnosis and the reduced need for IV antibiotic treatment in $\mathrm{CF}_{+\mathrm{RM}}$ compared to $\mathrm{CF}_{\text {classic }}$. However, it cannot be concluded that patients with a $\mathrm{RM}$ always have milder disease. In this group, $7 \mathrm{CF}_{+\mathrm{RM}}$ underwent lung transplantation. Moreover, the 64 detected RM comprise frameshift mutations, PTC mutations and large deletions, suggesting importantly disrupted and non-functional CFTR. As for most common CFTR-mutations, a broad range in severity of RM is seen and this is responsible for the wide range in phenotype in these individuals $[1,2]$. In the case of compound heterozygosity, the mildest mutation is known to be the most dominant on phenotype $[1,2,10]$.

Eighteen percent of the $\mathrm{CF}_{+\mathrm{RM}}$ had a sweat chloride < $60 \mathrm{mmol} / \mathrm{L}$. Further functional testing in these patients should be proposed in order to find out if both mutations are CF-causing and if CF-diagnosis in these individuals could be demonstrated. Data from the literature and CFTR1 suggest that most of the RMs found in our $\mathrm{CF}_{+\mathrm{RM}}$ with a sweat chloride $<60 \mathrm{mmol} / \mathrm{L}$ are related to CFTR-RD or are seen in asymptomatic subjects [7]. (See Additional file 1). However, based on registry data alone we will not be able to predict disease liability of a RM. Collecting clinical data and measuring CFTR-function in vivo and ex vivo in a prospective way in a large population will be the only way to get a better understanding
Table 5 Comparison of $\mathrm{CF}_{+\mathrm{RM}}$ with age and gender controlled

$\mathrm{CF}_{\text {classic }}$

\begin{tabular}{|c|c|c|c|}
\hline CCharacteristics & $\mathrm{CF}_{+\mathrm{RM}}$ & $\mathrm{CF}_{\text {classic }}$ & $p$-value \\
\hline Number (n) & 70 & 140 & \\
\hline Male & 37 (52.9\%) & $74(52.9 \%)$ & 1.0000 \\
\hline Adults & $46(65.7 \%)$ & 88 (62.9\%) & 0.6846 \\
\hline \multicolumn{4}{|l|}{ Mutation-distribution } \\
\hline $\begin{array}{l}\text { F508del } \\
\text { homozygous }\end{array}$ & $0(0.0 \%)$ & $129(92.1 \%)$ & - \\
\hline $\begin{array}{l}\text { F508del } \\
\text { heterozygous }\end{array}$ & $42(60.0 \%)$ & $0(0.0 \%)$ & - \\
\hline other & $28(40.0 \%)$ & $11(7.9 \%)$ & $<0.0001$ \\
\hline \multirow[t]{2}{*}{ Age (y) } & $27.6(11.9-37.3)$ & $26.1(13.2-33.7)$ & \\
\hline & $25.9(15.0)$ & $24.3(13.3)$ & 0.5406 \\
\hline \multirow[t]{2}{*}{ Age at diagnosis (y) } & $70(100 \%)$ & $140(100 \%)$ & \\
\hline & $3.7(0.3-18.3)$ & $0.3(0.1-2.0)$ & $<0.0001$ \\
\hline \multirow{2}{*}{$\begin{array}{l}\text { Sweat chloride } \\
\text { (mmol/L) }\end{array}$} & $64(91,4 \%)$ & $117(83.6 \%)$ & \\
\hline & $\begin{array}{l}96.3 \\
(63.7-107.0)\end{array}$ & $\begin{array}{l}104.0 \\
(97.1-115.0)\end{array}$ & $<0.0001$ \\
\hline
\end{tabular}

Sweat chloride

\begin{tabular}{llll} 
Missing & $6(8,6 \%)$ & $23(16.4 \%)$ & 0.1198 \\
$0-\leq 30 \mathrm{mmol} / \mathrm{L}$ & $3(4.3 \%)$ & $0(0 \%)$ & 0.0360 \\
$31-\leq 60 \mathrm{mmol} / \mathrm{L}$ & $11(15,7 \%)$ & $0(0 \%)$ & $<0.0001$ \\
$>60 \mathrm{mmol} / \mathrm{L}$ & $50(71,4 \%)$ & $117(83.6 \%)$ & $\mathbf{0 . 0 3 9 8}$ \\
FEV $_{1}$ pred & $59(84.3 \%)$ & $123(87.9 \%)$ & \\
& $76.7(57.8-95.9)$ & $68.4(48.1-85.6)$ & $\mathbf{0 . 0 1 6 6 ^ { * }}$ \\
& $76.8(25.4)$ & $67.4(24.1)$ & \\
BMI-Z score (Cachera) & $65(92.9 \%)$ & $145(97.9 \%)$ & \\
& $-0.3(-1.0-0.4)$ & $-0.5(-1.1-0.1)$ & 0.2059 \\
Patients with IV AB & $25(35.7 \%)$ & $71(50.7 \%)$ & $\mathbf{0 . 0 4 1 4}$ \\
Days of IV AB & $21.0(11.0-48.0)$ & $18.0(14.0-42.0)$ & 0.5690 \\
Pancreatic insufficiency & $39(55.7 \%)$ & $137(97.9 \%)$ & $<\mathbf{0 . 0 0 0 1}$ \\
Chronic PA & $17(24.3 \%)$ & $61(43.6 \%)$ & $\mathbf{0 . 0 0 9 3}$ \\
CF liver disease & $3(4.3 \%)$ & $8(5.7 \%)$ & $0.7551^{* *}$ \\
CFRD & $14(20.0 \%)$ & $32(22.9 \%)$ & 0.8432 \\
\hline
\end{tabular}

Data are presented in $\mathrm{n}(\%)$, Median (IQR) or mean (SD)

$p$-value: statistical significant if $<0.05$ bold

* Two sample t-test

** Fisher's exact test

${ }^{\infty}$ Fisher's exact test with continuity correction

Bonferroni adjusted threshold $P<0.01$

${ }^{a}$ Days of IV AB (antibiotics): in patients who received IV antibiotics

of the pathogenicity of RMs. This strategy is the goal of the CFTR3-project [31].

CF registries are of valuable use in studying CF populations in general and in comparing groups and trends in variables over time [32, 33]. However, the use of registry data has its limitations. Entering patients' data into a CF-registry does not necessarily imply that this person is affected with CF. Thomas et al. showed that not all registry patients fulfil predefined $\mathrm{CF}$ diagnostic criteria 
[34]. To get more accurate information in case of inconsistency, it is preferable to contact the CF-centre who entered these data, which was done accordingly in our study. Despite these efforts, some inconsistencies (ie. PI in patients with borderline sweat tests, typographical errors) remained unchanged. Previous publications have highlighted the problem of data quality in CF registries as a limitation of studies based on registries [1-3, 27, 34].

An important impediment we faced was the mixture of different nomenclatures for CFTR-mutations used in the BCFR2013. Berwouts and co-workers have shown that completing data in a consistent way by the molecular lab should be done when reporting a CFTR-variant. However, this is hardly the case and may result in misinterpretation [27]. Genetic labs should be aware of this and reports of CFTR-analysis should contain all information that is needed to avoid confusion [28]. Furthermore, CF-registries are mostly entered by CF-team members, who are not familiar with HGVSnomenclature. Misspelling of a mutation may also lead to errors and should be regularly checked.

Inconsistency in reporting variants lead to confusion in 5 of our cases. 2184AA > G and 2181AA > G were initially considered as a RM, as no match with a CFTR2, nor a CFTR1 variant was found. However, both are an alternative (not commonly accepted) description of 2183AA > G, being a CFTR2-mutation. The second ambiguous name was c.[1680-886A $>\mathrm{G}]$, better known as the old nomenclature name c. $1679+1.6 \mathrm{kbA}>\mathrm{G}$ (legacy name $1811+1.6 \mathrm{kbA}>\mathrm{G}$ ), being a CFTR2 mutation and earlier described by Chillon [35]. An alternative, but not commonly accepted nomination of IVS16977_IVS17b + 247del2514 was del exon 17. The four alternative nomenclatures we found were not the consequence of a misspelling at registry level. Entering an $\mathrm{ENaC}$ mutation as if it was a CFTR-mutation in the BCFR-2013 lead again to confusion. CF-registries do not provide the possibility to enter mutations at another level such as CFTR. Moreover, segregation analysis is needed to confirm the location of mutations in trans. This should always be stated in the final molecular report to avoid misdiagnosis [2, 36]. To overcome these limitations in the future, reporting CFTR-variants in CFregistries should be done in a meticulously way; avoiding typographical errors, entering c.DNA name, protein name and legacy name, if available, and confirming that both mutations are located in trans. This study shows that regular reviews by a geneticist in the CF-field would contribute to better reporting of RM in CF-registries and should therefore be encouraged.

\section{Conclusion}

This is the first national CF-registry study where data about RMs are collected and compared to classic CF-controls.
Whether a mutation could be assigned as a RM depends on the population and the timeframe in which the mutation is found. CFTR2 is continuously expanding. Mutations that are currently considered as a RM can become more common in the future because of a better reporting worldwide. We were able to identify 64 RMs in Belgium of which an important percentage had never been reported before. CF patients carrying at least one RM are more likely to have milder disease than classic CF patients. However, a wide range in disease severity is seen. Based on registry data alone, we will not be able to define the disease liability of a RM. Therefore, a prospective study, using electrophysiological tests in subjects with the identified RMs will be needed.

We can conclude that this survey is a first step in identifying CF-patients with RMs in a prospective way. Currently, patients with RMs do not have access to new CFTR-modulators nor can they participate in running clinical trials. Documenting the effect of the RM on CFTR-protein function will enable better classification of the RM with the aim to get access to personalized therapy in the future.

\section{Additional file}

Additional file 1: Table S1. CFTR mutations reported in the BCFR2013: translation into HGVS nomenclature (NM_000492.3) and additional information for CFTR1-RM with sweat chloride < 60 mmol/L. (DOCX 29 kb)

\begin{abstract}
Abbreviations
BCFR2013: Belgian CF-Registry of 2013; CF+RM: CF patient with at least 1 RM; CF $_{\text {classic: }}$ CF patient with 2 class 1-3 mutations (classic CF); HGVS: Human Genome Variation Society; Non-CFTR1RM: Rare mutations that have never been reported in the CFTR1-database until now (July2016); PWCF: people with Cystic Fibrosis; RM: Rare mutation; VCC: Varying clinical consequence
\end{abstract}

\section{Acknowledgements}

We thank all Belgian CF patients and their parents for accepting to enter their data in the Belgian CF-registry. We also thank all Belgian CF-centres for their contribution to the Belgian CF-Registry: UZAntwerpen-GZAntwerpen (S Verhulst, M Lequesne, V Nowé), UZ Leuven (K De Boeck, F Vermeulen, L Dupont), UZ Gent (F De Baets, S Van Daele), Hôpital Erasme-Huderf Bruxelles (G Casimir, L Hanssens, C Knoop, D Baran), Cliniques Universitaires St-LuC Bruxelles ( $P$ Lebecque), CHR de la Citadelle Liège - CHC Liège (JP Sacré, H Boboli, F Piérart). We thank $V$ Van Casteren, Head of Unit Health Services Research (Scientific Institute of Public Health, Brussels, Belgium).

We also thank C Castellani (Verona, Italy) and J Rommens (Toronto, Canada) for their help with c.[1680-886A > G] translation.

\section{Funding}

The Belgian CF registry is funded by the RIZIV-INAMI (Rijksinstituut voor ziekteen invaliditeitsverzekering - Intstitut national d'assurance maladie-invalidité). This research did not receive any specific grant from funding agencies in the public, commercial, or not-for-profit sectors. 


\section{Bibliography}

A part of this study was presented as an oral poster presentation during the 39th European Cystic Fibrosis Conference in Basel (2016) and published in the abstract book: J Cyst Fibr 2016; 15(S1); S35; WS 23.2.

\section{Author's contributions}

EDW and AM conceived and designed the study. EDW drafted the manuscript. SSW carried out the statistical analysis. MT and SSW managed data collection. EDW, SSW and MT managed data analysis and interpretation. SS helped in translating mutation names into HGVS nomenclature and helped with MT in quality control of the analysed data. All authors revised the manuscript critically and approved the final manuscript.

\section{Ethics approval and consent to participate}

Collection of the yearly CF-registry data is approved by the central Ethical committee for Belgium (B67020108649). Patients ( $\geq 18$ years) and parents from patients $<18$ years signed informed consent to have their data collected and entered into the database as a research tool. Registry data were compliant to Belgian data protection laws.

\section{Consent for publication}

Not applicable.

\section{Competing interests}

The authors declare that they have no competing interests.

\section{Publisher's Note}

Springer Nature remains neutral with regard to jurisdictional claims in published maps and institutional affiliations.

\section{Author details}

${ }^{1}$ CF Clinic, Universitair Ziekenhuis Brussel, Vrije Universiteit Brussel, Laarbeeklaan 101, 1090 Brussels, Belgium. ${ }^{2}$ Belgian CF Registry, Scientific Institute of Public Health (WIV-ISP), Brussels, Belgium. ${ }^{3}$ Department for Reproduction and Genetics, Centre of Medical Genetics, Universitair Ziekenhuis Brussel, Vrije Universiteit Brussel, Brussels, Belgium.

Received: 21 June 2017 Accepted: 10 August 2017

\section{Published online: 22 August 2017}

\section{References}

1. Zielenski J. Genotype and phenotype in cystic fibrosis. Respiration. 2000;67:117-33

2. Castellani C, Cuppens H, Macek M, Cassiman JJ, Kerem E, Durie P, et al. Consensus on the use and interpretation of cystic fibrosis mutation analysis in practice. J Cyst Fibros. 2008;7:179-96. doi:10.1016/j.jcf.2008.03.009.

3. Zemanick ET, Harris JK, Conway S, Konstan MW, Marshall B, Quittner AL, et al. Measuring and improving respiratory outcomes in cystic fibrosis lung disease: opportunities and challenges to therapy. J Cyst Fibros. 2010;9:1-16. doi:10.1016/j.jcf.2009.09.003.

4. Castellani C. CFTR2: how will it help care? Paediatr Respir Rev. 2013;14S:2-5. doi:10.1016/j.prrv.2013.01.006.

5. Simmonds NJ, D'Souza LD, Roughton M, Alton EWFW, Davies JC, Hodson ME. Cystic fibrosis and survival to 420 years: a study of cystic fibrosis transmembrane conductance regulator function. Eur Respir J. 2011:37:1076-82. doi:10.1183/09031936.00079010.

6. Kerem BS, Rommens JM, Buchanan JA, Markiewicz D, Cox TK, Chakravarti A, et al. Identification of the cystic fibrosis gene: genetic analysis. Science. 1989;245:1073-80.

7. http://www.genet.sickkids.on.ca version June 2016; last update 25 April 2011.

8. Sosnay PR, Siklosi KR, Van Goor F, Kaniecki K, Yu H, Sharma N, et al. Defining the disease liability of variants in the cystic fibrosis transmembrane conductance regulator gene. Nat Genet. 2013;45:1160-7. doi:10.1038/ng.2745.

9. De Boeck K, Zolin A, Cuppens H, Olesen HV, Viviani L. The relative frequency of CFTR mutation classes in European patients with cystic fibrosis. J Cyst Fibros. 2014;13:403-9. doi:10.1016/j.jcf.2013.12.003.

10. https://www.cftr2.org/sites/default/files/CFTR2_13August2015.pdf. 13th August 2015 version.

11. Sosnay PR, Salinas DB, White TB, Ren CL, Farrell PM, Raraigh KS, et al. Applying cystic fibrosis transmembrane conductance regulator genetics and CFTR2 data to facilitate diagnoses. J Pediatr. 2017;181S:S27-32. doi:10.1016/j.jpeds.2016.09.063.

12. Rosenstein BJ, Cutting GR. The diagnosis of cystic fibrosis: a consensus statement. J Pediatr. 1998;132(4):589-95.

13. Farrell PM, Rosenstein BJ, White TB, Accurso FJ, Castellani C, Cutting GR, et al. Guidelines for diagnosis of cystic fibrosis in newborns through older adults: cystic fibrosis foundation consensus report. J Pediatr. 2008;153(2):S4-S14. doi:10.1016/j.jpeds.2008.05.005.

14. Farrell PM, White TB, Ren CL, Hempstead SE, Accurso F, Derichs N, Howenstine M, et al. Diagnosis of cystic fibrosis: consensus guidelines from the cystic fibrosis foundation. J Pediatr. 2017;181S:S4-15. doi:10.1016/j.jpeds.2016.09.064.

15. Gobeau C, Wilschanski M, Skalicka V, Lebecque P, Southern KW, Sermet I, et al. Phenotypic characterization of patients with intermediate sweat chloride values: towards validation of the European diagnostic algorithm for cystic fibrosis. Thorax. 2009;64:683-91. doi:10.1136/thx.2008.104752.

16. De Boeck K, Wilschanski M, Castellani C, Taylor C, Cuppens H, Dodge J, et al. Cystic fibrosis: terminology and diagnostic algorithms. Thorax. 2006;61:627-35. doi:10.1136/thx.2005.043539.

17. Bombieri C, Claustres M, De Boeck K, Derichs N, Dodge J, Girodon E, et al. Recommendations for the classification of diseases as CFTR-related disorders. J Cyst Fibros. 2011;10(S2):S86-S102.

18. Beekman JM, Sermet-Gaudelus I, De Boeck K, Gonska T, Derichs N, Mall MA, et al. CFTR functional measurements in human models for diagnosis, prognosis and personalized therapy: report on the pre-conference meeting to the 11th ECFS basic science conference, Malta 26-29 March 2014. J Cyst Fibros. 2014;13(4): 363-72. doi:10.1016/j.jcf.2014.05.007.

19. Naehrlich L, Ballmann M, Davies J, Derichs N, Gonska T, Hjelte L, et al. Nasal potential difference measurements in diagnosis of cystic fibrosis: an international survey. J Cyst Fibros. 2014;13:24-8. doi:10.1016/j.jff.2013.08.006.

20. De Wachter E, De Schutter I, Meulemans A, Buyl R, Malfroot A. A semiblinded study comparing 2 methods of measuring nasal potential difference: subcutaneous needle versus dermal abrasion. J Cyst Fibros. 2016;15:60-6. doi:10.1016/j.jcf.2015.06.007.

21. Keenan K, Avolio J, Rueckes-Nilges C, Tullis E, Gonska T, Naehrlich L. Nasal potential difference: best or average result for CFTR function as diagnostic criteria for cystic fibrosis? J Cyst Fibros. 2015;14:310-6. doi:10.1016/j.jcf. 2014.09.006.

22. Rowe SM, Miller S, Sorscher EJ. Mechanisms of disease: cystic fibrosis. N Engl J Med. 2005;352:1992-2001.

23. WangX DDW, Wypij D, Fay ME, Ferris BG Jr. Pulmonary function between 6 and 18 years of age. Pediatr Pulmonol. 1993;15(2):75-88.

24. Hankinson JL, Odencrantz JR, Fedan KB. Spirometric reference values from a sample of the general U.S. population. Am J Respir Crit Care Med. 1999;159(1):179-87.

25. Rolland-Cachera MF, Cole TJ, Sempé M, Tichet J, Rossignol C, Charraud A. Body mass index variations: centiles from birth to 87 years. Eur J Clin Nutr. 1991:45:13-21.

26. Lee TW, Brownlee KG, Conway SP, Denton M, Littlewood JM. Evaluation of a new definition for chronic Pseudomonas aeruginosa infection in cystic fibrosis patients. J Cyst Fibros. 2003;2(1):29-34. doi:10.1016/\$15691993(02)00141-8.

27. Berwouts S, Morris M, Girodon E, Schwarz M, Stuhrmann M, Dequeker E. Mutation nomenclature in practice: findings and recommendations from the cystic fibrosis external quality assessment scheme. Hum Mutat. 2011:00:1-7. doi:10.1002/humu.21569.

28. den Dunnen DR, Maglott DR, Hart RK, Greenblatt MS, McGowan-Jordan J, et al. HGVS recommendations for the description of sequence variants: 2016 update. Hum Mutat. 2016;37:564-9. doi:10.1002/humu.22981.

29. Ooi CY, Dupuis A, Ellis L, Jarvi K, Martin S, Ray PN, et al. Does extensive genotyping and nasal potential difference testing clarify the diagnosis of cystic fibrosis among patients with single-organ manifestations of cystic fibrosis? Thorax. 2014;69:254-60. doi:10.1136/thoraxjnl-2013-203832.

30. Ooi CY, Dupuis A, Gonska T, Ellis L, Ni A, Jarvi K, et al. Does integration of various ion channel measurements improve diagnostic performance in cystic fibrosis? Annals ATS. 2014;11(4):562-70.

31. Derichs N. Personalized characterization of rare cystic fibrosis genotypes (CFTR3): Ongoing project within European Cystic Fibrosis Society Diagnostic Network Working Group (ECFS DNWG). https:// www.ecfs.eu/ecfs_dnwg

32. Burgel PR, Bellis G, Olesen HV, Viviani L, Zolin A, Blasi F, Elborn JS. On behalf of the ERS/ECFS task force on provision of care for adults with cystic fibrosis 
in Europe. Future trends in cystic fibrosis demography in 34 European countries. Eur Respir J. 2015;46:133-41. doi:10.1183/09031936.00196314.

33. Kerem E, Viviani L, Zolin A, MacNiell S, Hatziagorou E, Ellemunter H, et al. On behalf of the ECFS patient registry steering group. Factors associated with $\mathrm{FEV}_{1}$ decline in cystic fibrosis: analysis of the ECFS patient registry. Eur Respir J. 2014:43:125-33. doi:10.1183/09031936.00166412.

34. Thomas M, Lemonnier L, Gulmans V, Naehrlich L, Vermeulen F, Cuppens H, et al. Is there evidence for correct diagnosis in cystic fibrosis registries? J Cyst Fibros. 2014;13:275-80. doi:10.1016/j.jcf.2013.10.010.

35. Chillon M, Dörk T, Casals T, Giménez J, FonknechtenN WK, et al. A novel donor splice site in intron 11 of the CFTR gene, created by mutation 1811 $+1.6 \mathrm{kbA}>\mathrm{G}$, produces a new exon: high frequency in Spanish cystic fibrosis chromosomes and association with severe phenotype. Am J Hum Genet. 1995;56:623-9.

36. Bergougnoux A, Boureau-Wirth A, Rouzier C, Altieri JP, Verneau F, Larrieu L, et al. A false positive newborn screening result due to a complex allele carrying two frequent CF-causing variants. J Cyst Fibros. 2016;15:309-12. doi:10.1016/j.jcf.2016.04.003.

Submit your next manuscript to BioMed Central and we will help you at every step:

- We accept pre-submission inquiries

- Our selector tool helps you to find the most relevant journal

- We provide round the clock customer support

- Convenient online submission

- Thorough peer review

- Inclusion in PubMed and all major indexing services

- Maximum visibility for your research

Submit your manuscript at www.biomedcentral.com/submit
Biomed Central 